\title{
E-Cigarettes, Vaping Devices, and Acute Lung Injury
}

\author{
Nathan K Cobb and Jigna N Solanki
}

\author{
Introduction \\ History of E-Cigarettes \\ Pulmonary Toxicity of Vaping Devices \\ Acute Pulmonary Toxicity and E-Cigarette- or Vaping-Associated Lung \\ Injury \\ EVALI Presentation \\ EVALI Treatment \\ EVALI Outcomes \\ Discussion \\ Summary
}

\begin{abstract}
"E-cigarettes" are a class of consumer devices designed to deliver drugs, primarily nicotine or marijuana oils, to the lung by vaporization. Regulation of the devices in the United States is relatively minimal, and research on both epidemiology and potential toxicity has focused on nicotine devices. In 2019, an outbreak of an acute respiratory illness in the United States was traced back to the contamination of e-cigarette fluids with vitamin $\mathbf{E}$ acetate, which had been used to disguise the dilution of marijuana oils. The outbreak, termed "e-cigarette or vaping associated lung injury" by the U.S. Centers for Disease Control, was characterized by pulmonary infiltrates and hypoxia, which usually required hospitalization and, often, admission to ICUs. The syndrome sickened $>2,600$ people, mostly young men, and killed $>50$ people before it began to abate 6 months later. No current regulations exist to prevent a similar event with the same or different chemical contaminants. Absent such regulation, respiratory practitioners should be prepared to evaluate, identify, and treat future cases of acute lung toxicity from e-cigarettes. Key words: e-cigarettes; nicotine; marijuana; acute respiratory failure; EVALI; vitamin E. [Respir Care 2020;65(5):713-718. (C) 2020 Daedalus Enterprises]
\end{abstract}

\section{Introduction}

In the early summer of 2019 , an outbreak of respiratory disease, characterized by hypoxia and pulmonary infiltrates, and often progressing to fulminant respiratory failure, was identified in the United States. Over a period of $\sim 6$ months,

Drs Cobb and Solanki are affiliated with the Division of Pulmonary and Critical Care, Department of Medicine, Georgetown University School of Medicine, Washington, District of Columbia. Dr Cobb is affiliated with the Medstar Health Research Institute, Hyattsville, Maryland.

The authors have disclosed no conflicts of interest.

Correspondence: Nathan K Cobb MD. E-mail: nkc4@georgetown.edu.

DOI: $10.4187 /$ respcare. 07733 the epidemic was first tied to e-cigarettes in general, with suspicion eventually falling on cartridges that contained marijuana oils rather than nicotine, and, ultimately, in November of 2019, the U.S. Centers for Disease Control and Prevention (CDC) identified vitamin E acetate as the likely cause of the lung injury. During this period, $>2,600$ people were sickened, with the vast majority requiring hospitalization, $>50$ people died, and at least one person required a lung transplantation, which made the epidemic one of the worst cases of mass poisoning in U.S. history. ${ }^{1,2}$

This epidemic seemed to take the entire public health and medical communities by surprise; however, in hindsight, it seems less surprising given the lack of regulation on e-cigarettes and vaping devices as drug delivery devices, whether for nicotine or other drugs. Here, we briefly reviewed the evolution of e-cigarettes, their potential mechanisms of 


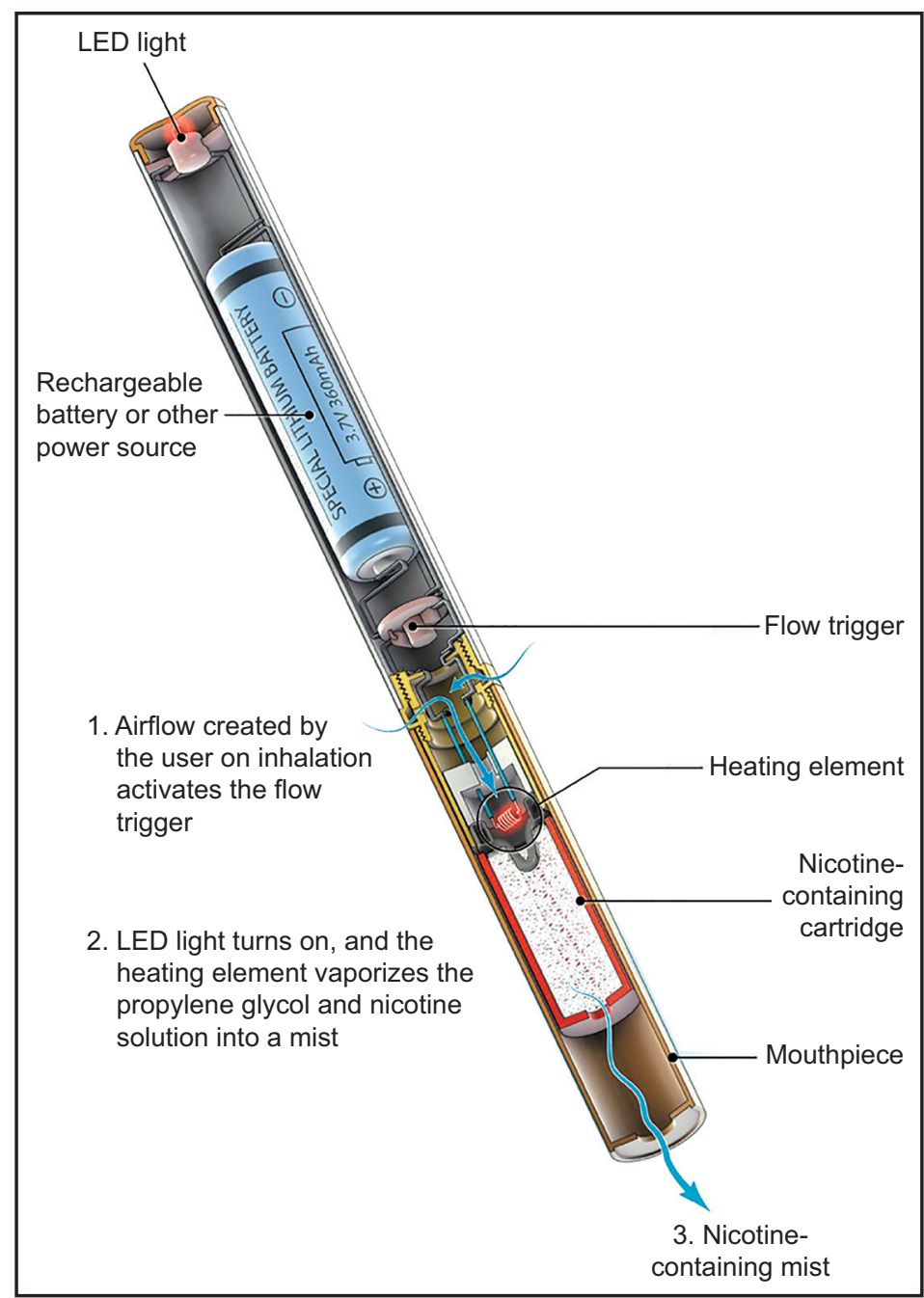

Fig. 1. Diagram of an e-cigarette. The cartridge is filled with plastic fibers soaked in nicotine solution and a humectant (usually propylene glycol). Flavoring may also be included. The devices typically have a battery, heating element, power source, and pressure switch, all embedded in a tube with a mouthpiece and access for cartridge insertion. From Reference 3, with permission.

toxicity in a typical formulation, and, ultimately, the risks of poisoning due to introduction of new or unknown chemicals.

\section{History of E-Cigarettes}

"E-cigarette" is a generic term for drug delivery devices that consist of a liquid-filled cartridge that contains a carrier solution (usually propylene glycol or vegetable glycerin), a vaporization chamber, heating element, and battery. When users inhale, a vaporized fluid that contains the solution, flavorings, and any additional chemicals or heating byproducts is delivered to the respiratory tract. ${ }^{3}$ Although early variants mimicked traditional combusted tobacco cigarettes, later devices come in different shapes and sizes, and may not be readily recognizable as an e-cigarette. A typical e-cigarette is shown in Figure 1.
The first commercial e-cigarettes were created in China, in 2003, for nicotine administration, and, by 2006, early versions were being sold in the United States and touted as smoking-cessation aids. ${ }^{4}$ Initial regulatory efforts to ban importation and sale of the devices were legally challenged, and, ultimately, sales were permitted in the United States as tobacco products as long as the devices are not marketed for therapeutic effect. ${ }^{5}$ Although most regulatory and scientific focus has been on nicotine e-cigarettes, their use to deliver other drugs, primarily tetrahydrocannabinol (THC) (the psychoactive component in marijuana) has been documented since the market introduction of these devices. ${ }^{6}$

Regulatory differences among countries have led to markedly different product profiles. European Union regulations limit the nicotine concentration to $20 \mathrm{mg} / \mathrm{mL}$, provide safety and quality standards, and ban certain ingredients. ${ }^{5}$ The United States, by contrast, to date, has taken a hands- 
off regulatory approach to the contents, recently banning most flavorings in non-refillable cartridges but otherwise imposing no such requirements for safety or limits on nicotine concentration. This has led to the development of much higher-yield devices in the United States, with concentrations as high as $50 \mathrm{mg} / \mathrm{mL}^{7}$ High-yield devices, in turn, may partially explain the explosion of use of e-cigarettes in young people in the United States. Between 2017 and 2019, the number of U.S. 12th graders who were vaping nicotine jumped from $11 \%$ to $25 \%,{ }^{8}$ concurrent with the increasing sales of high concentration products such as Juul (Juul Labs, San Francisco, California). ${ }^{9}$ Meanwhile, youth vaping rates in the United Kingdom seemed to remain stable from 2017 through 2018, at $\sim 9 \% .^{10}$

Research over the past decade has focused almost exclusively on nicotine-containing e-cigarettes. Few studies have attempted to determine rates of THC or marijuana oil use, despite the apparent popularity of the devices. Data from the Monitoring the Future study ${ }^{11}$ released at the height of the epidemic showed that the numbers of 12th graders who were vaping marijuana oil in the past 30 days had nearly tripled, from 5\% in 2017 to $14 \%$ in $2019 .{ }^{11}$ Dual use seems to be common; $20 \%$ of high school students who used nicotine e-cigarettes were found to have also used marijuana e-cigarettes in the 2014 survey in Connecticut ${ }^{12}$; whereas a separate 2017 survey of adult e-cigarette users found similar rates. ${ }^{13}$ Evidence from social media, including a study of Twitter (Twitter, San Francisco, California) posts in 2018 suggested that marijuana was one of the most popular topics in discussions of e-cigarettes. ${ }^{14}$ Together, there is evidence that, although vaping of marijuana oils is not as common as vaping of nicotine, it, nonetheless, is widespread and overlaps with nicotine use.

\section{Pulmonary Toxicity of Vaping Devices}

The long-term health effects of using e-cigarettes remain unknown, in part, due to the lack of manufacturing standards, which makes predicting pulmonary exposure for the generic class of e-cigarette devices nearly impossible. Nicotine devices predominantly contain propylene glycol and/or vegetable glycerin as carrier solutions. E-cigarettes used for other drugs may use different solutions and chemicals to drive aerosolization of the active drug, none of which have been extensively studied.

Propylene glycol is a known respiratory irritant, ${ }^{15}$ and exposure to e-cigarette vapor has been shown to cause an increase in air-flow resistance and a decrease in exhaled nitrous oxide. ${ }^{16}$ Known carcinogens identified in e-cigarette vapor include tobacco-specific nitrosamines (in nicotine ecigarettes), carbonyls (formalin, acrolein, and acetaldehyde), volatile organic compounds, and metals. ${ }^{17}$ Not all toxins detected in vapor are present in the solutions, rather they are produced as a byproduct of the heating and vaporization process. In most cases, these carcinogens are detected at levels significantly lower than combusted tobacco smoke. ${ }^{17}$ Additives, including flavorings, may introduce additional toxicity. Flavorings seem to appeal to youth, ${ }^{18}$ and the manufacturers market a mean of 49 flavors, with estimated thousands of different variations. ${ }^{19}$ Sweet and cinnamon flavors contain diacetyl, a compound associated with bronchiolitis obliterans, ${ }^{20}$ whereas cherry flavors contain benzaldehyde, a known respiratory irritant. ${ }^{21}$

Although often classified together with nicotine e-cigarettes based on the similarity of the delivery devices, e-cigarettes that deliver marijuana oils may have dissimilar solution profiles beyond just the active drug. ${ }^{22}$ Although there is a regulated supply chain for nicotine that stems from its use in pharmaceutical smoking cessation products, marijuana and THC products remain illegal under U.S. federal law, which prevents a similar supply chain. Despite this lack of known parity, potential long-term toxicity from marijuana vaping products is generally assumed to look similar to that of nicotine e-cigarettes.

\section{Acute Pulmonary Toxicity and E-Cigarette- or Vaping-Associated Lung Injury}

Previously, the acute effects of e-cigarettes were primarily thought to be limited to respiratory irritation. A small number of case reports had associated e-cigarettes with lipoid pneumonia, ${ }^{23}$ eosinophilic pneumonia, ${ }^{24}$ and hypersensitivity pneumonitis. ${ }^{25}$ However, the bulk of concern remained concentrated on the long-term effects in the model of combusted tobacco smoke.

However, in 2019 the CDC detected a few, and then a surge of cases of acute lung injury in e-cigarette users. The patients in the initial index cases presented with respiratory failure and gas exchange abnormalities, with many admitted to the ICU. Conditions in these patients were heterogenous, ranging from mild infiltrates and dyspnea to organizing pneumonia and bronchiolitis obliterans. ${ }^{26}$ The CDC termed the respiratory syndrome e-cigarette or vaping-associated lung injury (EVALI) as it struggled to identify a cause. Analysis of early data suggested a link to the use of solutions that contained marijuana oils. However, the majority of these patients also used nicotine vaping devices, although some denied (or were unaware of) use of marijuana fluids, ${ }^{1}$ which delayed communication of a conclusion to the public.

Ultimately, EVALI was firmly tied to vitamin E acetate ( $\alpha$-tocopheryl acetate), a synthetic form commonly used in dermatologic products, for example, sunscreens. In e-cigarettes, vitamin $\mathrm{E}$ has been used to thicken marijuana oil to disguise its dilution (being cut) with other substances. ${ }^{27}$ Initially, the $\mathrm{CDC}$ detected vitamin $\mathrm{E}$ in submitted 

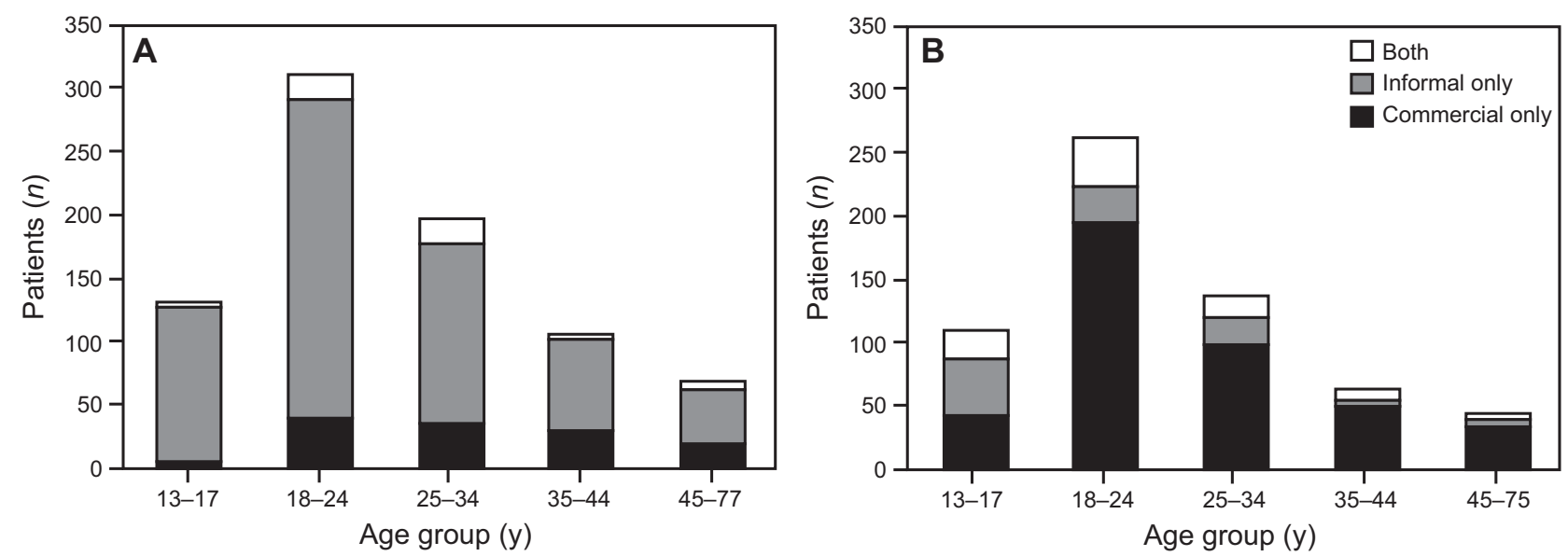

Fig. 2. Patient-reported product sources by age group among patients hospitalized with e-cigarette or vaping-associated lung injury (EVALI) A: tetrahydrocannabinol (THC) sources; and B: nicotine sources. From Reference 36, with permission.

marijuana vaporizer fluid samples and eventually confirmed it in 48 of 51 bronchioalveolar lavage samples, along with THC or metabolites in the majority of these samples. ${ }^{28}$ Little is known about the pulmonary toxicity of vitamin E; however, it has been postulated to disrupt alveolar surfactant, which leads to decreased surface tension, alveolar collapse, and lung injury. Vitamin E may also represent a marker for undetected heating byproducts, for example, ketene, that cannot currently be measured in BAL fluid. ${ }^{27}$

\section{EVALI Presentation}

As of January 2020, the CDC had reports of $>2,600$ cases of EVALI requiring hospitalization. The percentage of patients hospitalized for EVALI in the United States from August 2019 to January 2020 are depicted in Figure 2. The case definition includes a history of vaping within 90 days, imaging showing lung injury, the absence of infection, and an absence of a plausible alternative diagnosis. Patients have tended to be male $(66 \%)$ and younger, with a mean age of 24 years. ${ }^{1}$ Primary presenting concerns are nonspecific respiratory symptoms, including cough, dyspnea, or chest pain. Symptoms seem to develop over a period of days to weeks, and may include constitutional symptoms, such as fatigue, fever, weight loss, or gastrointestinal symptoms. ${ }^{29}$

More than half of the patients with EVALI were tachycardic and had room air oxygen saturation $>95 \%$. A lung examination is largely non-specific and does not correlate with the severity of disease. ${ }^{30}$ Abnormal imaging is the norm, with bilateral opacities in all patients and groundglass opacities seeming to be characteristic. ${ }^{26}$ Pathology samples are consistent with acute lung injury, including diffuse alveolar damage, pneumonitis, and organizing pneumonia but without a predominant form. ${ }^{31}$ Leukocytosis is common, as is some transaminitis. ${ }^{26}$

Alternative diagnoses should be ruled out by obtaining basic blood work (complete blood cell count, hepatic function panel, respiratory virus panel, serum inflammatory markers). Bronchoscopy with bronchoalveolar lavage is useful to exclude infectious or inflammatory causes of respiratory failure but not required for diagnosis. Urine toxicology, including for THC, may be useful in narrowing the diagnosis. ${ }^{29}$

\section{EVALI Treatment}

The CDC has provided treatment guidance for patients with EVALI that emphasizes the role of general supportive care. $^{2,29,30}$ Patients suspected of having EVALI should be hospitalized if their oxygen saturation is $<95 \%$ on room air; the vast majority of these patients required in-patient admission. ${ }^{2}$ Antibiotics, antivirals, and steroids are recommended on a case-by-case basis. ${ }^{29}$ Steroids have been used in most case series, with treating physicians attributing improvement to the drugs. ${ }^{26}$ There are no current recommendations on dose, duration, or intravenous versus oral preparations. Intubation, or even extracorporeal membrane oxygenation, ${ }^{32}$ may be required. Discharge only after clinical stability is assured, and prompt out-patient follow-up is recommended. ${ }^{2}$

\section{EVALI Outcomes}

Cases of EVALI peaked in September 2019 and began to rapidly decline, with few cases detected by January $2020 .{ }^{1}$ In total, there were $>50$ deaths, with an approximate mortality rate of $2 \%$ for hospitalized patients. ${ }^{33}$ Nearly half of admitted patients required ICU admission and $20 \%$ may proceed to endotracheal intubation. ${ }^{30}$ There 
are case reports of patients who required extracorporeal membrane oxygenation ${ }^{32}$ and at least one patient required lung transplantation. ${ }^{34}$

\section{Discussion}

The current epidemic of e-cigarette-associated acute lung injury can best be understood as a mass poisoning that resulted from the contamination of a consumer product, in this case, e-cigarette fluids. Due to high-quality regulation of food and drug products, mass poisonings from consumer products are rare in the United States. However, in 1937, $>100$ people died when diethylene glycol was used by the Massengill Corporation to create a sulfa drug antibiotic syrup known as elixir sulfanilamide. The modern FDA was founded as a reaction to the Massengill episode, with new laws that required proof of safety of drugs before their release and created a regulatory structure that would prevent future and similarly deadly events. ${ }^{35}$ Although the risks, morbidity and mortality of combustible tobacco are well understood today, e-cigarettes and vaping devices represent a class of drugs and devices that do not fit neatly into any pattern recognizable for the average American. Many Americans may assume that, when they purchase a vaping device or liquids, there is some assurance that the products are safe. In reality, no significant federal regulations exist that limit the chemicals used in e-cigarettes, determine how manufacturers test their products, or even require the manufacturers to assure the safety of their supply chains.

Vaping of marijuana oils may be less common than vaping of nicotine, but it has been noted since the first iterations of e-cigarettes appeared on the market, ${ }^{3}$ and as many as $15 \%$ of teenagers actively vape marijuana oils. The varying status of marijuana in many states (ranging from illegal to medically regulated to entirely legal), despite federal laws against its use and distribution, may make contamination more likely given the black market nature of the national supply chains, and, given the ubiquity of vaping devices, particularly among youth, we may see additional drugs being administered through vaping devices.

The rapid end to the EVALI epidemic is presumably linked to both behavioral changes on the part of users of ecigarettes (avoiding certain products) but, potentially, also, the washout of products that contain vitamin $\mathrm{E}$ from the market. This, however, does not preclude another similar event from a different contaminant. Although the contamination of marijuana vaping products has been a catastrophic event, a similar error that affects the supply chain for nicotine e-cigarettes could be markedly worse.

\section{Summary}

At the end of the day, acute lung injury as a result of vaporized drugs may represent a new normal, at least until state and federal regulations change. Respiratory practitioners who see a patient with new, acute respiratory symptoms will need to be vigilant about asking about e-cigarettes and vaping, and should be prepared to inquire explicitly about vaping solutions, their contents, and where they were acquired.

\section{REFERENCES}

1. Krishnasamy VP, Hallowell BD, Ko JY, Board A, Hartnett KP, Salvatore PP, et al; Lung Injury Response Epidemiology/Surveillance Task Force. Update: characteristics of a nationwide outbreak of e-cigarette, or vaping, product use-associated lung injury-United States, August 2019-January 2020. MMWR Morb Mortal Wkly Rep 2020;69 (3):90-94

2. Evans ME, Twentyman E, Click ES, Goodman AB, Weissman DN, Kiernan E, et al.; Lung Injury Response Clinical Working Group. Update: interim guidance for health care professionals evaluating and caring for patients with suspected e-cigarette, or vaping, product useassociated lung injury and for reducing the risk for rehospitalization and death following hospital discharge-United States. MMWR Morb Mortal Wkly Rep 2020;68(5152):1189-1194.

3. Cobb N, Abrams DB. E-cigarette or drug-delivery device? Regulating novel nicotine products. N Engl J Med 2011;365(3):193-195.

4. Hajek P, Etter JF, Benowitz N, Eissenberg T, McRobbie H. Electronic cigarettes: review of use, content, safety, effects on smokers and potential for harm and benefit. Addiction 2014;109(11):1801-1810.

5. Caponnetto P, Saitta D, Sweanor D, Polosa R. What to consider when regulating electronic cigarettes: pros, cons and unintended consequences. Int J Drug Policy 2015;26(6):554-559.

6. Cobb NK, Byron MJ, Abrams DB, Shields PG. Novel nicotine delivery systems and public health: the rise of the "e-cigarette." Am J Public Health 2010;100(12):2340-2342.

7. Jackler RK, Ramamurthi D. Nicotine arms race: JUUL and the highnicotine product market. Tob Control 2019;28(6):623-628.

8. Miech R, Johnston L, O'Malley PM, Bachman JG, Patrick ME. Trends in adolescent vaping, 2017-2019. N Engl J Med 2019;381 (15):1490-1491.

9. King BA, Gammon DG, Marynak KL, Rogers T. Electronic cigarette sales in the United States, 2013-2017. JAMA 2018;320(13):13791380.

10. Hammond D, Reid JL, Rynard VL, Fong GT, Cummings KM, McNeill A, et al. Prevalence of vaping and smoking among adolescents in Canada, England, and the United States: repeat national cross sectional surveys. BMJ 2019;365:12219.

11. Miech RA, Patrick ME, O'Malley PM, Johnston LD, Bachman JG. Trends in reported marijuana vaping among US adolescents, 2017 2019. JAMA 2020;323(5):475-476.

12. Morean ME, Kong G, Camenga DR, Cavallo DA, Krishnan-Sarin S. High school students' use of electronic cigarettes to vaporize cannabis. Pediatrics 2015;136(4):611-616.

13. Morean ME, Lipshie N, Josephson M, Foster D. Predictors of adult ecigarette users vaporizing cannabis using e-cigarettes and vape-pens. Subst Use Misuse 2017;52(8):974-981.

14. Allem JP, Majmundar A, Dharmapuri L, Cruz TB, Unger JB. E-liquid-related posts to Twitter in 2018: thematic analysis. Addict Behav Rep 2019;10:100196.

15. Wieslander G, Norbäck D, Lindgren T. Experimental exposure to propylene glycol mist in aviation emergency training: acute ocular and respiratory effects. Occup Environ Med 2001;58(10):649-655.

16. Vardavas CI, Anagnostopoulos N, Kougias M, Evangelopoulou V, Connolly GN, Behrakis PK. Short-term pulmonary effects of using an electronic cigarette: impact on respiratory flow resistance, impedance, and exhaled nitric oxide. Chest 2012;141(6):1400-1406. 
17. Pisinger C, Døssing M. A systematic review of health effects of electronic cigarettes. Prev Med 2014;69:248-260.

18. Zare S, Nemati M, Zheng Y. A systematic review of consumer preference for e-cigarette attributes: flavor, nicotine strength, and type. PLoS One 2018;13(3):e0194145

19. Zhu SH, Sun JY, Bonnevie E, Cummins SE, Gamst A, Yin L, Lee M. Four hundred and sixty brands of e-cigarettes and counting: implications for product regulation. Tob Control 2014;23(Suppl 3):iii3-iii9.

20. Allen JG, Flanigan SS, LeBlanc M, Vallarino J, MacNaughton P, Stewart JH, Christiani DC. Flavoring chemicals in e-cigarettes: diacetyl, 2, 3-pentanedione, and acetoin in a sample of 51 products, including fruit-, candy-, and cocktail-flavored e-cigarettes. Environ Health Perspect 2016;124(6):733-739.

21. Kosmider L, Sobczak A, Prokopowicz A, Kurek J, Zaciera M, Knysak J, et al. Cherry-flavoured electronic cigarettes expose users to the inhalation irritant, benzaldehyde. Thorax 2016;71(4):376-377.

22. Giroud C, de Cesare M, Berthet A, Varlet V, Concha-Lozano N, Favrat B. E-cigarettes: a review of new trends in cannabis use. Int $\mathrm{J}$ Environ Res Public Health 2015;12(8):9988-10008.

23. McCauley L, Markin C, Hosmer D. An unexpected consequence of electronic cigarette use. Chest 2012;141(4):1110-1113.

24. Arter ZL, Wiggins A, Hudspath C, Kisling A, Hostler DC, Hostler JM. Acute eosinophilic pneumonia following electronic cigarette use. Respir Med Case Rep 2019;27:100825.

25. Sommerfeld CG, Weiner DJ, Nowalk A, Larkin A. Hypersensitivity pneumonitis and acute respiratory distress syndrome from e-cigarette use. Pediatrics 2018;141(6). pii: e20163927.

26. Layden JE, Ghinai I, Pray I, Kimball A, Layer M, Tenforde MW, et al. Pulmonary illness related to e-cigarette use in Illinois and Wisconsin preliminary report. N Engl J Med 2020;382:903-916.

27. Blount BC, Karwowski MP, Shields PG, Morel-Espinosa M, Valentin-Blasini L, Gardner $\mathrm{M}$, et al; Lung Injury Response Laboratory Working Group. Vitamin E acetate in bronchoalveolarlavage fluid associated with EVALI. N Engl J Med 2020;382 (8):697-705

28. Blount BC, Karwowski MP, Morel-Espinosa M, Rees J, Sosnoff C, Cowan E, et al. Evaluation of bronchoalveolar lavage fluid from patients in an outbreak of e-cigarette, or vaping, product use- associated lung injury - 10 states, August-October 2019. MMWR Morb Mortal Wkly Rep 2019;68(45):1040-1041.

29. Jatlaoui TC, Wiltz JL, Kabbani S, Siegel DA, Koppaka R, Montandon $\mathrm{M}$, et al; Lung Injury Response Clinical Working Group. Update: interim guidance for health care providers for managing patients with suspected e-cigarette, or vaping, product use-associated lung injury United States, November 2019. MMWR Morb Mortal Wkly Rep 2019;68(46):1081-1086.

30. Siegel DA, Jatlaoui TC, Koumans EH, Kiernan EA, Layer M, Cates JE, et al; Lung Injury Response Epidemiology/Surveillance Group. Update: interim guidance for health care providers evaluating and caring for patients with suspected e-cigarette, or vaping, product use associated lung injury - United States, October 2019. MMWR Morb Mortal Wkly Rep 2019;68(41):919-927.

31. Butt YM, Smith ML, Tazelaar HD, Vaszar LT, Swanson KL, Cecchini MJ, et al. Pathology of vaping-associated lung injury. N Engl J Med 2019;381(18):1780-1781.

32. Maddock SD, Cirulis MM, Callahan SJ, Keenan LM, Pirozzi CS, Raman SM, Aberegg SK. Pulmonary lipid-laden macrophages and vaping. N Engl J Med 2019;381(15):1488-1489.

33. Mikosz CA, Danielson M, Anderson KN, Pollack LA, Currie DW, Njai R, et al; Lung Injury Response Epidemiology/Surveillance Task Force. Characteristics of patients experiencing rehospitalization or death after hospital discharge in a nationwide outbreak of e-cigarette, or vaping, product use-associated lung injury-United States, 2019. MMWR Morb Mortal Wkly Rep 2020;68(5152):1183-1188.

34. Shamus KJ.17-year-old is first vape-injured patient in U.S. to undergo double lung transplant. Detroit Free Press. 2019. Available at:https:// www.freep.com/story/news/local/michigan/2019/11/12/vaping-lunginjury-transplant-henry-ford-hospital-detroit/2575262001/.Accessed November 12, 2019

35. Wax PM. Elixirs, diluents, and the passage of the 1938 Federal Food, Drug and Cosmetic Act. Ann Intern Med 1995;122(6):456-461.

36. Ellington S, Salvatore PP, Ko J, Danielson M, Kim L, Cyrus A, et al; Lung Injury Response Epidemiology/Surveillance Task Force. Update: product, substance-use, and demographic characteristics of hospitalized patients in a nationwide outbreak of e-cigarette, or vaping, product useassociated lung injury - United States, August 2019-January 2020. MMWR Morb Mortal Wkly Rep 2020;69(2):44-49. 